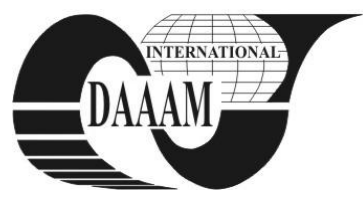

Annals of DAAAM for 2011 \& Proceedings of the 22nd International DAAAM Symposium, Volume 22, No. 1, ISSN 1726-9679 ISBN 978-3-901509-83-4, Editor B. Katalinic, Published by DAAAM International, Vienna, Austria, EU, 2011 Make Harmony between Technology and Nature, and Your Mind will Fly Free as a Bird

Annals \& Proceedings of DAAAM International 2011

\title{
MECHANICAL PROPERTIES OF COMPOSITES REINFORCED WITH NATURAL FIBRE FABRICS
}

\author{
TERCIU, O[vidiu] M[ihai]; CURTU, I[oan]; STANCIU, M[ariana] D[omnica] \& CERBU, C[amelia]
}

\begin{abstract}
The paper presents some experimental research results from testing composite materials reinforced with natural fibres fabrics, subjected to tensile stress. The research aims to determine the main mechanical properties of new materials necessary to simulate the behaviour of structures made of these natural fibre reinforced materials. Aspects regarding influence of layers orientation of natural fibres fabrics are presented

Key words: composite materials, tensile tests, weave fabrics, natural fibres, epoxy resin
\end{abstract}

\section{INTRODUCTION}

In the recent years, due to negative environmental effects of plastic and metal materials, which are heavily degradable, there are worldwide concerns for producing composite structures reinforced with natural fibres (Bismarck et al., 2006). One of the essential requirements to achieve this material structure is the compatibility between natural fibres used for reinforcing the composite material and the matrix (Kim et al., 2006; Cristaldi et al., 2010). Moreover it is essential having the possibility of obtaining materials with predetermined properties and a unitary structure. Unlike composites reinforced with a layer of random fibres, called mat fabric, weave fabrics reinforced composites offer some advantages such as: durability and impact resistance, the possibility to have different material thickness given by the number of used layers, the orientation of the layers for obtaining superior properties in certain directions and the possibility of adding other materials filling between layers to improve thermal and acoustic insulation properties and reduce weight of parts made from these materials (Nemr et al, 2011). New composite materials are present on the market as lower priced products, compared with the classic products and are being used for special purposes such as the automotive industry.

\section{MATERIALS AND METHODS}

The material called FEO (Flex/Epoxy/Oak) has a matrix of epoxy resin reinforced with flax fibres fabrics, for example type $14 / 1(14$ yarns $/ 1 \mathrm{~cm})$ in the warp and weft, and in the matrix was added as filler, oak or spruce wood flour, as can be seen in Figure 1.

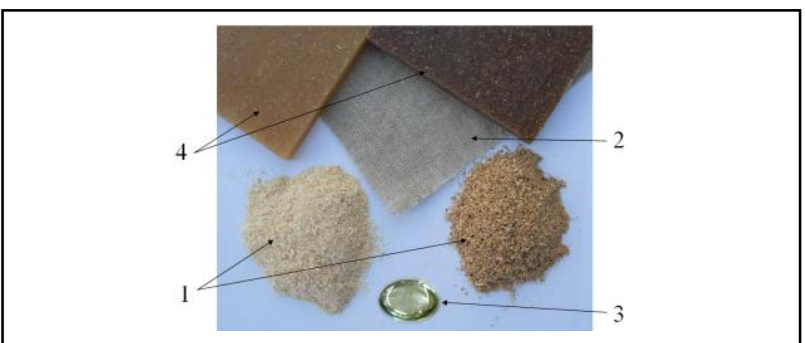

Fig. 1. Material composition: 1 - wood flour (oak and spruce species); 2 - weave fabric of flax fibres; 3 - epoxy resin; 4 composite materials
Plates from which were taken samples were manufactured by handing lay-up process of 6 layers reinforced with flax fibres fabrics, arranged in the same direction towards the longitudinal direction of the plate. The fibres fabric is formed of warp and weft direction and was placed on the length of the plate with warp yarns. In Figure 2.a can be see both directions of the yarns, the warp and weft. From the composite plates were cut for tensile tests, six samples in longitudinal direction of the plate and five samples in transverse direction of the plate (Fig. 2.b), and other two sets of five specimens for determining Poisson's ratio. The samples have the specific shape and dimensions of tensile test composite materials reinforced with fibre, according to ASRO SR EN ISO 527 (Cerbu et al., 2008).

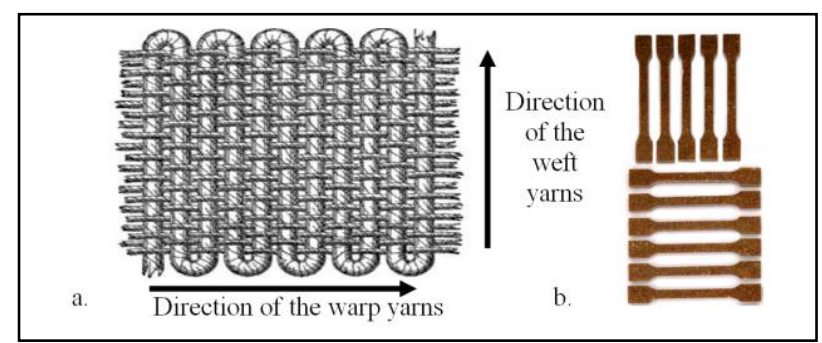

Fig. 2. Cut direction of samples depending on orientation of the plain weave fabric (a) and the samples for tensile tests (b)

Tensile test is known to be the most important and commonly used static test due to the procedure's simplicity on obtaining the strength and stiffness characteristics.

The equipment used is a tensile test machine with constant speed, provided with specimen fixing devices. In order to measure the specific elongation of the specimen was used an extension measuring instrument and in order to determine Poisson's ratio was used digital image correlation (DIC) method (Fig. 3.b)

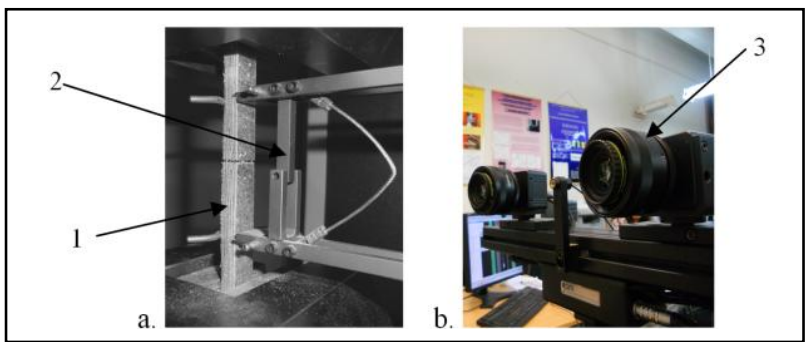

Fig. 3. Tensile testing devices (a) and a digital image correlation system (b): 1 - composite material specimen; 2 extension measuring instrument; 3 - ARAMIS system cameras for capture images

\section{RESULTS AND DISCUSSION}

After processing the machine data, tensile tests diagrams $(F-\Delta L)$ were made, as presented in Figure 4. Breaking force varies depending on the direction from where the specimen was 
cut. For specimens cut on longitudinal (warp yarns) direction the force ranges from $1.53 \mathrm{kN}$ to $2.18 \mathrm{kN}$ and for the ones cut on the weft direction, it ranges from $2.42 \mathrm{kN}$ to $2.94 \mathrm{kN}$.

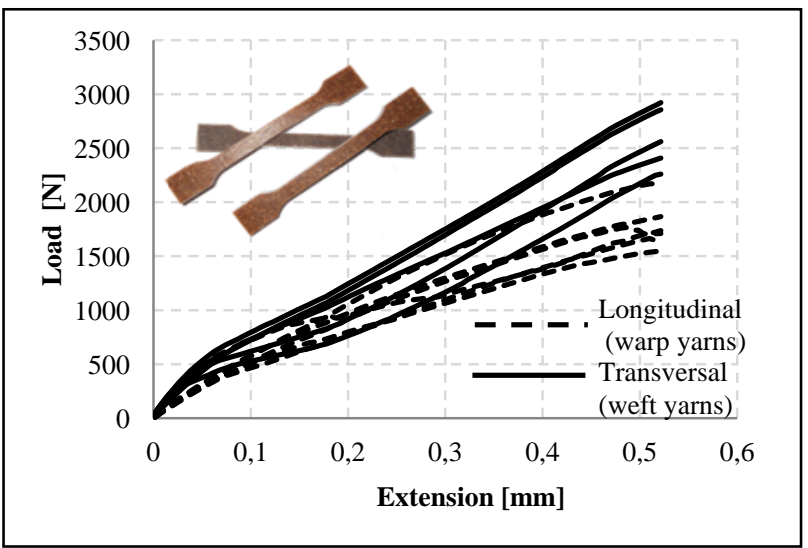

Fig. 4. Tensile tests diagrams

Figure 5 presents variations in tensile strength of specimens cut on both directions. Tests showed that the material had a better resistance when applied in the direction of the weft yarns fabric used to reinforce composites. On the longitudinal direction of the plate was recorded maximum tensile strength of 32.57 $\mathrm{MPa}$ and on the transverse direction of the plate was recorded a tensile strength of $42.03 \mathrm{MPa}$.

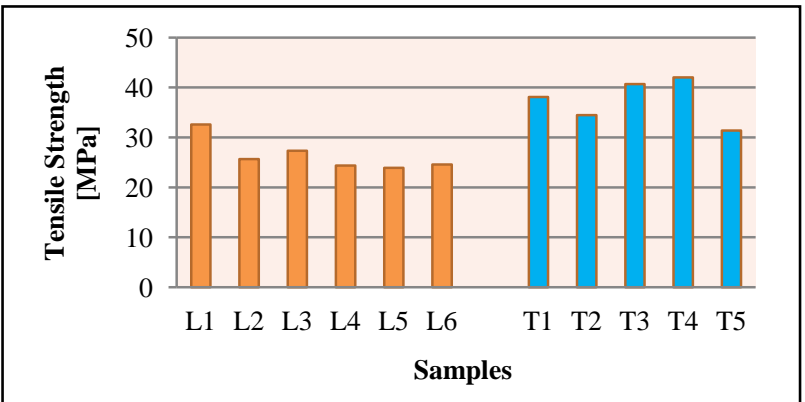

Fig. 5. Variation of tensile strength for both types of specimens (longitudinal and transversal)

Table 1 presents the mechanical properties of the material, for the two-way direction of stresses applied, both longitudinally and transversally. Although natural fibre fabric has a symmetrical construction on both directions, type 14/1, tests revealed significant differences in mechanical properties of the two directions.

\begin{tabular}{|l|c|c|}
\hline $\begin{array}{c}\text { Mechanical properties } \\
\text { of lignocelluloses material } \\
\text { studied (FEO) }\end{array}$ & $\begin{array}{c}\text { Average value } \\
\text { for the warp } \\
\text { direction }\end{array}$ & $\begin{array}{c}\text { Average value } \\
\text { for the weft } \\
\text { direction }\end{array}$ \\
\hline Stiffness, $N / m$ & 7259254.27 & 9155033.62 \\
\hline Young's Module, $M P a$ & 8657.566 & 10417.946 \\
\hline Stress at Maximum Load, $M P a$ & 26.3973 & 37.3317 \\
\hline Strain at Maximum Load & 0.00403 & 0.003698 \\
\hline $\begin{array}{l}\text { Energy absorbed by the } \\
\text { specimen, } N m m\end{array}$ & 105569.098 & 135815.622 \\
\hline Load at Break, $k N$ & 1.7774 & 2.6033 \\
\hline Stress at Break, $M P a$ & 26.0802 & 37.1255 \\
\hline Strain at Break & 0.0041 & 0.00345 \\
\hline Poisson's ratio & 0.3371 & 0.3395 \\
\hline
\end{tabular}

Tab. 1. Mechanical properties results from tests

The absorbed energy required to produce a fracture, per area unit or mechanical work done during the break, per area unit is equal with area under the curve $\sigma=f(r)$, as shown in Figure 6 . Tests have shown that the energy absorbed by the specimen is greater when the material is applied in the direction of the weft yarn fabric, as shown in Figure 6.

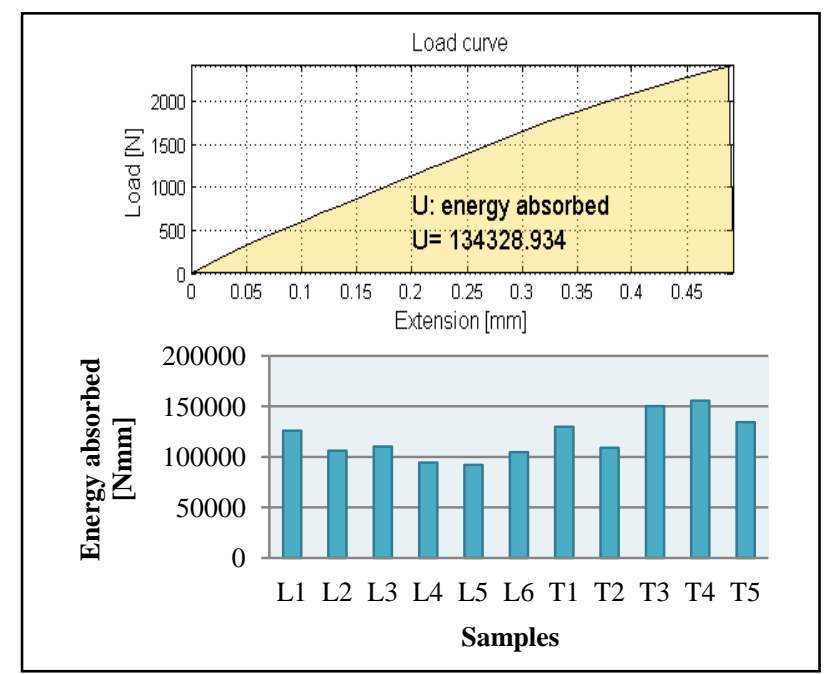

Fig. 6. Variation of energy absorbed for both types of specimens (longitudinal and transversal)

\section{CONCLUSION}

Knowledge of mechanical properties on both directions of composite materials reinforced with natural fibre fabrics is very useful to designers, to make advanced structures, with applications to interior automotive components and furniture with complex shapes. One of the advantages of the proposed composite material is that it can make automotive interior components with visible surfaces and a natural texture and colour change material can only be achieved by replacing the wood species used as filler particles.

Natural fibre reinforced composites are materials of the future, sustainable and biodegradable with minimal effects on the environment.

\section{ACKNOWLEDGEMENTS}

This paper is supported by the Sectoral Operational Programme Human Resources Development (SOP HRD), financed from the European Social Fund and by the Romanian Government under the contract number POSDRU/88/1.5/S/59321

\section{REFERENCES}

Bismarck, A.; Baltazar, A.; Jimenez, Y. \& Sarikakis, K. (2006). Green composites as panacea? Socio-economic aspects of green materials, Available from: http://www.springerlink .com, Accessed: 2011-06-23

Cerbu, C.; Ciofoaia, V. \& Curtu, I. (2008). The effects of manufacturing on the mechanical characteristics of the Eglass/epoxy composites, Proceedings of TMT 2008, pp. 229-232, ISBN 974-9958-617-41-6, Istanbul

Cristaldi, G.; Latteri, A.; Recca, G. \& Cicala, G. (2010). Composites Based on Natural Fibre Fabrics, Woven Fabric Engineering, Published by Sciyo, Rijeka, November 2010, pp.317-342, ISBN 978-953-307-194-7, Croatia

Kim, J.P.; Yoon, T.H.; Mun, S.P.; Rhee, J.M. \& Lee, J.S. (2006). Wood-polyethylene composites using ethylenevinyl alcohol copolymer as adhesion promoter, Available from: http://www.sciencedirect.com, Accessed: 2011-07-01

Nemr, E.H.; Brice, M.M. \& Dheilly, R.M.(2011). Development of thermal insulating and sound absorbing agro-sourced materials from auto linked flax-tows, Available from: http://www.sciencedirect.com, Accessed: 2011-07-17 